\title{
Polycrystalline Yttrium Aluminum Garnet Fibers from Colloidal Sols
}

Department of Materials Science and Engineering, University of Michigan, Ann Arbor, Michigan

48109

\begin{abstract}
Polycrystalline yttrium aluminum garnet (YAG) fibers were prepared from commercially available colloidal sols of $\mathrm{Y}_{2} \mathrm{O}_{3}$ and $\mathrm{AlOOH}$ and water-soluble polymers. The fibers were dry spun and all processing was performed in air. Transformation to $\mathrm{YAG}$ was complete by $\cong 1300^{\circ} \mathrm{C}$, and the fibers were mostly dense by $1600^{\circ} \mathrm{C}$ with a final fired diameter of $120 \mu \mathrm{m}$. A bend test was used to characterize mechanical strength, and an average of $522 \pm 186 \mathrm{MPa}$ with a Weibull modulus of 3.5 was determined. The bend stress relaxation (BSR) test was used to characterize creep properties. The creep resistance was better than that of all commercially available oxide fibers with the exception of Saphikon singlecrystal alumina ( $c$-axis oriented). The creep strain of the YAG fibers compared well with that calculated for YAG monoliths with roughly the same grain size.
\end{abstract}

\section{Introduction}

$\mathrm{T}_{\mathrm{i}}^{\mathrm{s}}$ HE efficiency of gas turbine engines can be substantially improved by increased operating temperatures. This can be achieved by replacing superalloy components within the hot section with equivalent components made of ceramics. The successful application of ceramics in the field of propulsion requires creep resistance, strength retention to temperatures above $1370^{\circ} \mathrm{C}$, and damage tolerance. For this reason, there is much interest in the development of creep-resistant ceramic fibers which are suitable as the reinforcing phase in CMCs. A number of very high quality ceramic fibers are available commercially. However, many of these exhibit a sharp drop in strength between $1200^{\circ}$ and $1400^{\circ} \mathrm{C}^{1,2}$ when tested in an oxidizing atmosphere. Also, the issues of chemical compatibility and thermal expansion mismatch between the fiber and matrix are central to the successful incorporation of the fibers into the matrix.

The last several years have seen increased interest in developing materials with inherently better high-temperature properties than those of currently available materials. One such study, performed by Corman, focused specifically on identifying oxides with better properties than alumina. Corman investigated the creep properties of a number of single-crystal oxides and identified yttrium aluminum garnet (YAG) as exceptionally creep resistant. ${ }^{3}$ At $1700^{\circ} \mathrm{C}$ and a stress of $100 \mathrm{MPa}$, the creep rate of [111]-oriented single-crystal YAG was found to be one order of magnitude lower than $c$-axis oriented alumina at $1700^{\circ} \mathrm{C}$. Furthermore, the creep rate of YAG single crystals was only weakly dependent on orientation, while alumina single crystals were strongly anisotropic. Parthasarathy $\mathrm{et}_{\mathrm{al}}^{4,5}$ investigated the creep behavior of hot-pressed polycrystalline YAG with a $3 \mu \mathrm{m}$ grain size and found it to have a lower creep rate than that calculated for polycrystalline alumina with a similar grain size. An earlier study using the same material ${ }^{6}$ showed

R. J. Kerans-contributing editor

\footnotetext{
Manuscript No. 193508. Received June 10, 1994; approved February 18, 1995.

Supported by the U.S. Air Force Systems Command, Wright-Patterson AFB, under Contract No. F33615-91-C-5650.

Member, American Ceramic Society.
}

that the fracture strength of YAG was nearly constant over the range $25^{\circ}-1400^{\circ} \mathrm{C}$. Directionally solidified $\mathrm{Al}_{2} \mathrm{O}_{3}-\mathrm{Y}_{3} \mathrm{Al}_{5} \mathrm{O}_{12}$ eutectic composites have been shown to exhibit even better high-temperature properties. ${ }^{7,8}$

Although its potential as a matrix material has been investigated, there is relatively little known about the behavior of YAG fibers, as those which exist are still in the developmental stages. The creep behavior of YAG fibers prepared using alkoxide solgel precursors has been reported, ${ }^{9}$ although processing details have not been published. Alumina-YAG eutectic fibers have been produced using an edge-defined film-fed growth technique $^{10}$ and exhibit properties substantially better than those reported for monolithic ceramics prepared in a similar manner.

The goal of the present work was to investigate techniques for preparing polycrystalline YAG fibers from colloidal sols. Preliminary characterization of the fibers was performed through the use of a bend test to characterize strength and the bend stress relaxation (BSR) technique to characterize creep resistance. The BSR results are compared directly to the results of similar tests performed on commercially available oxide fiber. The BSR results are then used to make uniaxial predictions which are compared to the compressive creep results obtained by Parthasarathy et al. ${ }^{5}$

\section{Fiber Processing}

A schematic of the processing steps involved in making the YAG fibers is shown in Fig. 1. The steps were (1) compounding the raw materials, (2) drying the sols to form a stock powder, (3) rehydrating the powders to an appropriate rheology for spinning, (4) dry spinning the green fibers, and (5) firing the green fibers to burn off the binder and sinter the fibers.

\section{(1) Raw Materials}

The raw materials used were quite simple and commercially available. Colloidal sols of $\mathrm{Y}_{2} \mathrm{O}_{3}$ and AlOOH (pseudo-bohemite) (colloidal yttria and AL-20 colloidal alumina, Nyacol Products, Ashland, MA) were used as the oxide sources. The sols contained colloidal particles with diameters of $5 \mathrm{~nm}\left(\mathrm{Y}_{2} \mathrm{O}_{3}\right)$ and $50 \mathrm{~nm}(\mathrm{AlOOH})$, and were stabilized at a $\mathrm{pH}$ of 7.0 for the $\mathrm{Y}_{2} \mathrm{O}_{3}$ and 4.0 for the AlOOH. ${ }^{11}$ As a result of the different isoelectric points, an inhomogeneous floc structure formed rapidly when the two sols were mixed. This floc structure was not fiber forming, making it necessary to add spinning aids to the sols. This approach differs from the usual alkogel approach to fibers, in which the gel structure itself provides the rheological properties necessary for spinning. The floc structure in colloidal sols is the result of electrostatic attractions between particles and is easily broken by the high degree of shear which the fluid must undergo during spinning.

$\mathrm{X}$-ray diffraction revealed that powders formed from simply mixed, flocced sols contained significant amounts of unreacted yttria and alumina as well as $\mathrm{YAlO}_{3}$ and $\mathrm{Y}_{2} \mathrm{Al}_{4} \mathrm{O}_{9}$, even at temperatures as high as $1650^{\circ} \mathrm{C}$. The amounts of these phases were comparable to those observed in a phase development study using ball-milled $\mathrm{Al}_{2} \mathrm{O}_{3}$ and $\mathrm{Y}_{2} \mathrm{O}_{3}$ powders. ${ }^{12}$ This stands in sharp contrast to the direct conversion from precursor to YAG at $900^{\circ} \mathrm{C}$ observed in atomically mixed carboxylates. ${ }^{13}$ This pointed to gross inhomogeneities in the simply mixed materials, indicating that attraction between like particles was 


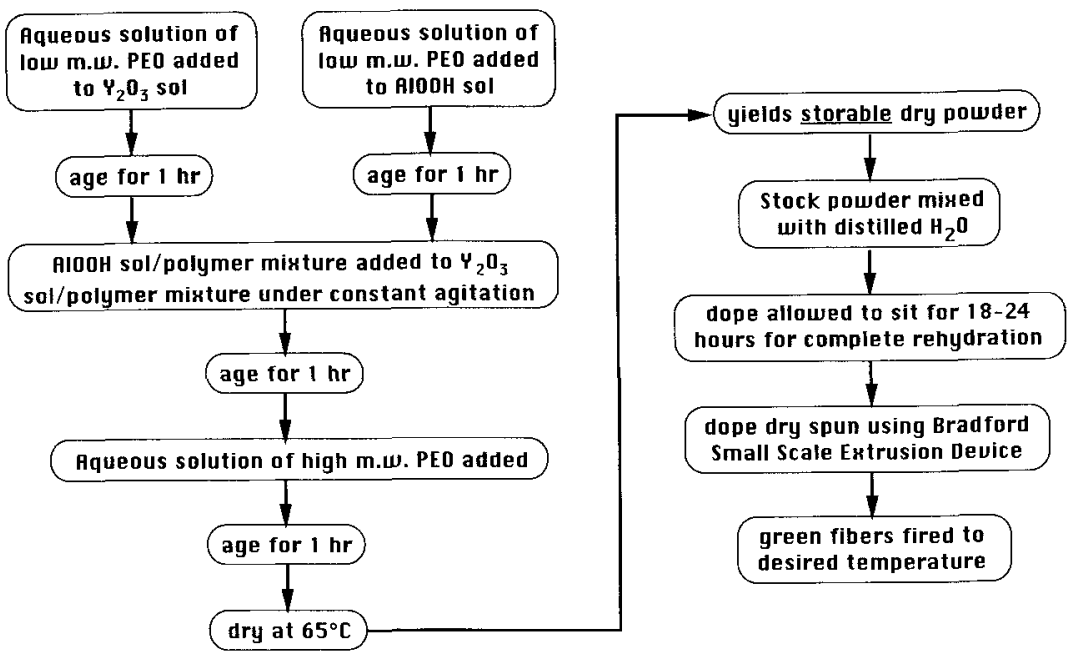

Fig. 1. Fiber processing flowchart.

greater than attraction between differing particles. It was found that the addition of water-soluble polymers to each sol prior to mixing effectively shielded the particles from interacting with each other, as indicated by complete conversion to YAG at high temperatures. Clearly, phase development in the $\mathrm{Al}_{2} \mathrm{O}_{3}-\mathrm{Y}_{2} \mathrm{O}_{3}$ system is dominated by the scale of mixing.

Several different water-soluble polymers were investigated, both as spinning aids and as colloidal stabilizers, including polyvinyl pyrrilidone (PVP) (GAF Chemicals, Wayne, NJ), polyethylene glycol (PEG) (CARBOWAX, Union Carbide, Danbury, CT), and polyethylene oxide (PEO) (POLYOX, Union Carbide). PVP was found to be an acceptable colloidal stabilizer, but dopes prepared with it were difficult to concentrate. Much of the early work on this project involved PVP, but only short lengths of fiber were obtained, and uniformity between batches was poor. PEG was an effective stabilizer only when present in quantities exceeding 50 vol\% (dry weight basis). PEO, on the other hand, was an effective stabilizer at low molecular weights and an effective spinning aid at high molecular weights. Additionally, a novel method of preparing spinnable dopes with PEO was discovered. As fibers prepared with PVP as the stabilizer/spinning aid have been previously reported, ${ }^{12,13}$ the remainder of this paper will focus solely on fibers prepared with PEO.

\section{(2) Dope Preparation and Fiber Spinning}

Dopes were prepared by first adding the low molecular weight grade of the PEO (WSR-205, mol wt $=600000$ ) to each of the sols in the amount dry polymer/dry ceramic $=0.2$. This polymer was found to effectively stabilize the sol mixture when added to each sol approximately $1 \mathrm{~h}$ before mixing. Next, the two sol + polymer mixtures were mixed under gentle stirring. At this point, the high molecular weight grade of PEO (WSR-303, mol wt $=7000000$ ) was added in the amount dry polymer/dry ceramic $=0.05$. This polymer was an excellent spinning aid at very low concentrations. However, as a result of its extremely high molecular weight, it is also a coagulant; thus, it was necessary to delay adding it to the dope until after the stabilizing polymer had been added. The final mixture of sols + polymer was dried at $65^{\circ} \mathrm{C}$, yielding a highly agglomerated powder.

The powder was storable and was easily rehydrated by the addition of distilled water. This last point had an important impact on the reproducibility of this method. The sol-polymer mixtures were very difficult to concentrate by conventional techniques, such as rotary evaporation, due to the high viscosity of the dopes. As the viscosity increased during concentration, large amounts of material were often lost into the condenser of the rotary evaporator when large bubbles burst. Since water content was determined by monitoring evaporative weight loss, the loss of material into the condenser meant a loss of the reference point. At even higher viscosities, the dopes formed a hard crust where the dope contacted the evaporation flask. This was presumed to be a result of slow water transport through the extremely viscous dope. As a result of these problems, it was difficult to concentrate the dope to a viscosity sufficient for spinning, the dope was often inhomogeneous, and water content was unknown. Using the rehydration technique, however, the water content was known exactly and a much more homogeneous dope was obtained. This technique is also of general interest, as it is unique among sol systems in that irreversible gelation does not occur on drying, due to the high degree of polymer loading in the system.

After the addition of distilled water, the dope was allowed to stand for 18-24 h to allow complete rehydration. At this point, the dope was very spinnable. Spinning was performed under ambient conditions using a laboratory scale fiber extrusion device (Bradford University Research, Ltd., U.K.) equipped with a $150 \mu \mathrm{m}$ spinneret. The spin line could support little draw; thus, the green fiber diameter was controlled by the spinneret diameter. The length of the spin line was too short to completely dry the fiber, so the fibers could not be spooled. The green fibers were collected in $\cong 1 \mathrm{~m}$ lengths and allowed to dry in room-temperature air.

\section{(3) High-Temperature Processing}

The high-temperature processing of the fibers was straightforward. Although a heating rate of $20^{\circ} \mathrm{C} / \mathrm{min}$ was often used to fire green fibers, they could be fired at heating rates at least as high as $50^{\circ} \mathrm{C} / \mathrm{min}$ with no observed defects, due to gas evolution during binder burnout. However, the fibers tended to develop kinks in the axial direction if fired in the absence of tension, and any curvature present in the green fiber became more pronounced. This did not present a problem in terms of microstructural characterization, but the unknown stress state present in such fibers during bending would have led to erroneous results in the mechanical and creep resistance evaluations. Straight fibers were prepared for these tests by constraining the ends of green fibers with small pieces of alumina refractory during firing. As the fiber shrank during sintering, the refractory piece was dragged along with it, maintaining the tension. This treatment resulted in straight fibers which were used for strength and creep testing. Approximately $35 \%$ shrinkage was observed between the length of green and fired fibers. $20 \%$ axial shrinkage was observed between dried green fibers, which were approximately $150 \mu \mathrm{m}$ in diameter and fired fibers which were approximately $120 \mu \mathrm{m}$ in diameter.

\section{Characterization}

\section{(1) Microstructural Characterization}

(A) Phase Development: Phase development in the fibers was characterized by X-ray diffraction using monochromatic 
$\mathrm{Cu} K \alpha$ radiation (Rigaku Rotaflex diffractometer). XRD samples were produced by grinding fibers which had been fired for $1 \mathrm{~h}$ at temperatures between $900^{\circ}$ and $1700^{\circ} \mathrm{C}$ into a fine powder. After firing to $900^{\circ} \mathrm{C}$, the diffraction pattern is weak, but reveals a mixture of yttria and $\gamma$-alumina. Between $1000^{\circ}$ and $1400^{\circ} \mathrm{C}$, a gradual transition from yttria and $\gamma$-alumina to phase-pure YAG is observed, with several intermediate phases. This is shown in Fig. 2. After firing to $1400^{\circ} \mathrm{C}$ and above, only phase-pure YAG is present.

(B) Grain Growth and Sintering: Microstructural characterization was performed using an SEM equipped with a field emission gun (Hitachi S-800 scanning electron microscope). Fibers were fired to temperatures between $1000^{\circ}$ and $1700^{\circ} \mathrm{C}$ and held for $1 \mathrm{~h}$. Fibers fired below $1300^{\circ} \mathrm{C}$ were extremely porous, both on the surface and in the interior. Average grain and pore sizes were not determined for these firing temperatures, because the microstructure represented a mixture of phases and because of the small size of the grains $(<<0.18 \mu \mathrm{m})$. In fibers fired to higher temperatures, densification of the interior was qualitatively observed to lag behind pore closure on the surface. This influenced grain growth, as grains on the fiber surface tended to be larger than those in the interior. Despite these differences, quantitative measurements of pore and grain sizes were made only for the fiber surfaces, due to the difficulty associated with preparing fiber cross sections for microstructural examination.

Fibers fired to $1300^{\circ} \mathrm{C}$ exhibited pores $67 \mathrm{~nm}$ in size covering $3.9 \%$ of the surface, and a grain size of $0.18 \mu \mathrm{m}$. The interior exhibited open porosity. After firing to $1400^{\circ} \mathrm{C}$, the surface pores were isolated and $83 \mathrm{~nm}$ in size and covered $1.6 \%$ of the surface. The grain size was $0.25 \mu \mathrm{m}$, and the interior still exhibited interconnected porosity. These features are shown in Figs. 3(a) and (b). The surface (3(a)) reveals a nearly dense microstructure with a uniform grain size. The fracture surface (3(b)) also appears uniform, although with much interconnected porosity. The fiber surfaces were fully dense after $1500^{\circ} \mathrm{C}$, although porous regions were occasionally observed in the cross section. These porous regions exhibited much smaller grains than the surrounding material. The grain size of the fibers was $0.51 \mu \mathrm{m}$. After firing to $1600^{\circ} \mathrm{C}$, only isolated pores were observed in the cross section, and a grain size of $1.5 \mu \mathrm{m}$ was observed. After $1700^{\circ} \mathrm{C}$, the fibers were fully dense in the cross section with the exception of large voids attributed to inhomogeneity in the dope prior to spinning. A grain size of $3.2 \mu \mathrm{m}$ was observed. Figures 4(a) and (b) show a typical fiber surface and fracture surface of a fiber fired to $1700^{\circ} \mathrm{C}$. The surface of the fiber reveals equiaxed grains with a fairly uniform grain size. The fracture surface reveals that the fiber is generally

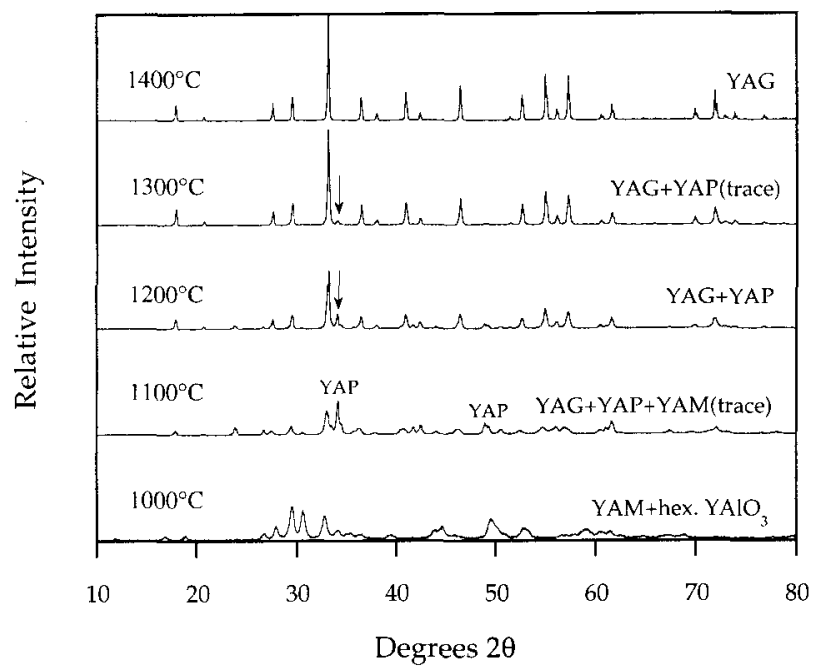

Fig. 2. X-ray diffraction patterns for fibers spun from colloidal sols and fired to various temperatures for $1 \mathrm{~h}$. The fibers are nearly pure YAG after $1300^{\circ} \mathrm{C}$ firing. dense, although large voids are present, and the fiber exhibits a round cross section.

Grain size data taken from fibers fired to temperatures between $1400^{\circ}$ and $1700^{\circ} \mathrm{C}$ could be fit to

$$
D^{2}-D_{0}^{2}=K t
$$

where

$$
K=K_{0} e^{-Q / R T}
$$

consistent with normal grain growth kinetics. $D_{0}$ was taken to be the grain size of fibers fired to $1300^{\circ} \mathrm{C}$, and $t$ was $3600 \mathrm{~s}$ $(1 \mathrm{~h})$. The agreement between the data and the curve fit was excellent, with an apparent activation energy of $540 \mathrm{~kJ} / \mathrm{mol}$ (Fig. 5). It is interesting to note that this value compares well with the activation energy of $584 \mathrm{~kJ} / \mathrm{mol}$ determined by Parthasarathy et al. for the kinetics of creep of polycrystalline YAG monoliths with a grain size of $3 \mu \mathrm{m} .^{4}$

(C) Microstructural Defects: Several defects which could limit the strength of the fibers were observed, primarily on fracture surfaces of the fibers. Large voids on the inside of the fiber were occasionally noted, as well as large, radial cracks which appeared on the fiber axis. These defects stemmed from three different sources, all processing related. Large voids were related to the dope homogeneity. They formed either due to agglomerations within the sols or due to incompletely dissolved polymer. It is likely that these defects are the result of incompletely redispersed powder during the preparation of the dope for spinning. Improvements in the processing of the dope could eliminate these defects.

Radial cracks were related to drying shrinkage of the green fibers and did not occur during the heat treating process. There were several observations which pointed to this conclusion. First, central cracks were often observed on green fibers, which resembled the cracks observed in fired fibers. Furthermore, no additional cracking was noted on firing, whether the green fibers contained cracks or not. The appearance of cracks appeared to be related to the age of the green fibers; fibers which were examined in the SEM several hours after spinning exhibited no cracks, while those examined several days after spinning did. Finally, central cracks were never observed in fibers spun from an $80 \mu \mathrm{m}$ spinneret, but were often seen in those spun from the $150 \mu \mathrm{m}$ spinneret. Thus, it would appear that water evaporation was a time-dependent process on the order of several days, and the strain imposed on a green fiber due to drying was sufficient to cause fracture in thick sections.

Surface defects likewise arose from multiple sources. Agglomerations or undissolved polymer identical to those causing internal voids could just as easily have been located on the surface. Indeed, large voids located at or very near the surface were observed on fracture surfaces examined in the SEM and were typically associated with very low fracture strengths. Other surface defects could have originated at any point between spinning and firing. There were several steps which involved handling the fibers, and cracks could easily have formed as a result. The firing process itself (for straight fibers) required the fibers to be in contact with an alumina substrate while moving across its surface. There was ample opportunity for defects to be introduced at this time. If the process were run continuously with adequate drying length to collect $d r y$ green fiber and continuous fiber sintering was employed, many of these defects could be avoided.

\section{(2) Room-Temperature Bend Strength}

The strength of the fibers was characterized using a bend test similar to others described in the literature. ${ }^{14.15}$ The bend test fixture, shown in Fig. 6, consisted simply of a clear, flexible plastic ruler clamped on one end and free to move on the other. The fiber to be tested was attached to the ruler, using small rubber bands, and the ruler was then bent into a circle to impose a bending stress on the fiber. The fiber accurately followed the shape of the ruler, allowing the radius of bending measured from the ruler to be used as the radius of bending of the fiber. 


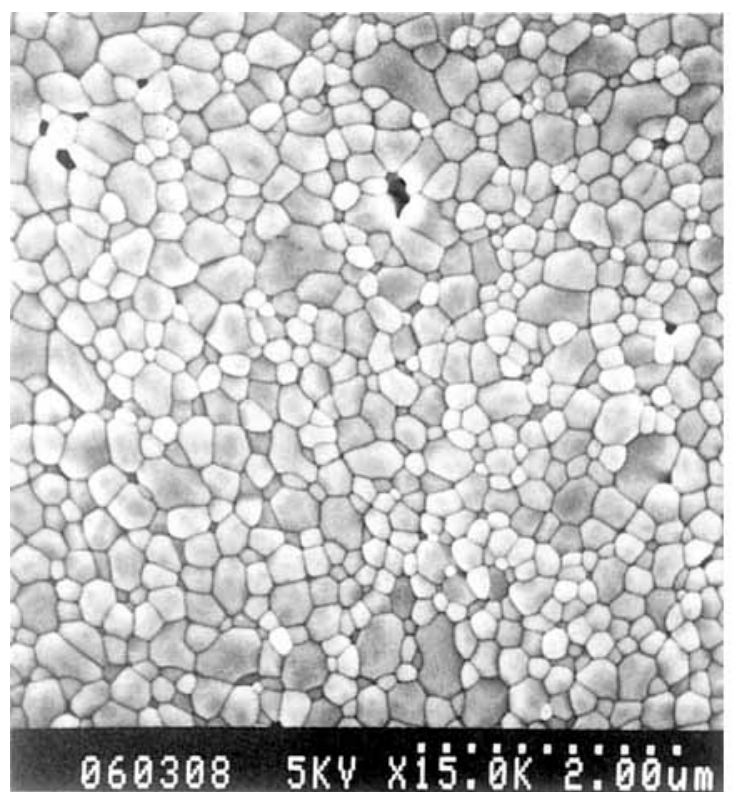

(a)

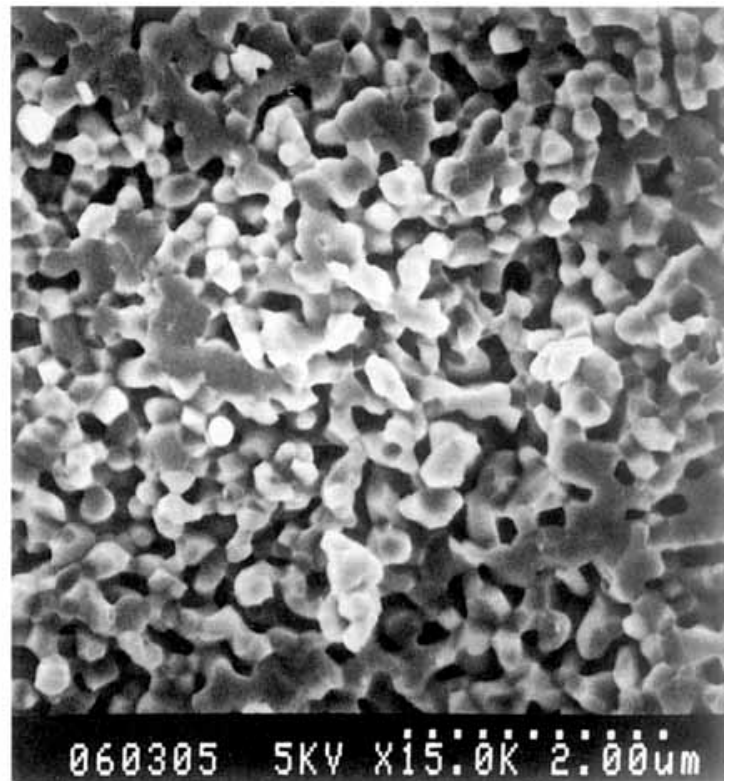

(b)

Fig. 3. SEM micrographs of fibers fired to $1400^{\circ} \mathrm{C}$ for $1 \mathrm{~h}(15000 \times)$. As-fired surface (a) is nearly dense and exhibits a uniform grain size. Fracture surface (b) has regions which are dense, but mostly contains interconnected porosity.

The bending stress was increased by pulling the free end of the ruler slowly to decrease the radius of bending, until fracture occurred. At this point the test was stopped, the radius of curvature was measured, and the bend stress at fracture was calculated. There was approximately $4 \%$ error in the test due to inaccuracies in measuring the radius, and the test was $98 \%$ repeatable. Assuming pure bending, the magnitude of the stress at any point within the fiber was given by

$$
\sigma(z, R)=\frac{E z}{\rho}
$$

where $z$ is the distance from the centroidal axis, $\rho$ is the bending radius, and $E$ is Young's modulus. It was assumed that the fibers would always fracture at the point of maximum tensile stress on the outer edge of the fiber on the tensile side; thus, $z$ was replaced with the fiber radius in the preceding equation. An average fiber radius of $120 \mu \mathrm{m}$ was determined using the SEM and was used in all calculations. $E$ was assumed to be the same as for the bulk material, $283 \mathrm{GPa} .{ }^{16}$ Over 70 tests of this sort were performed.

The average bending stress was found to be $522 \pm 186 \mathrm{MPa}$. The large standard deviation is a result of a small Weibull modulus, discussed further below. SEM examination of the fracture surfaces revealed that fracture initiated at defects at or near the surface, without exception. A typical fracture surface is shown in Fig. 7. Large internal defects occasionally were

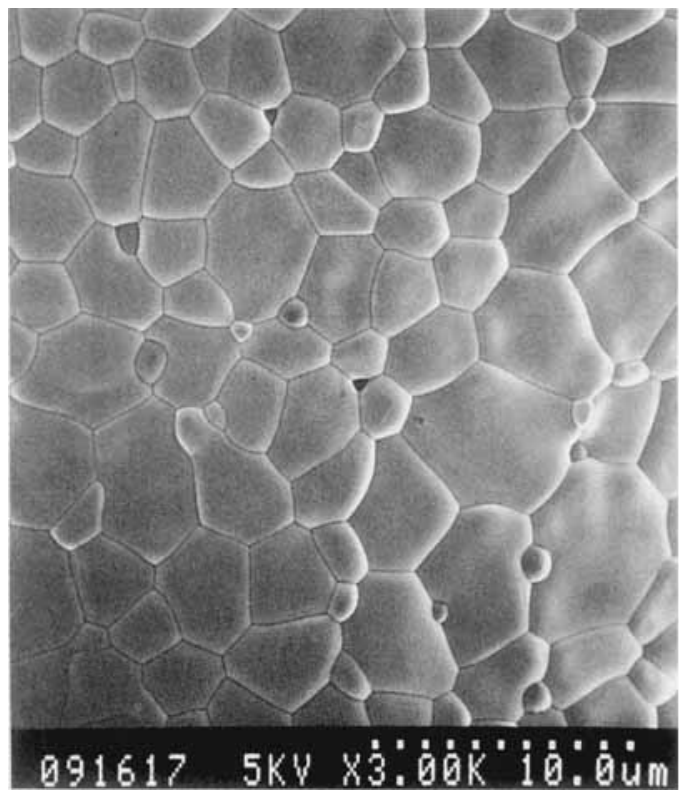

(a)

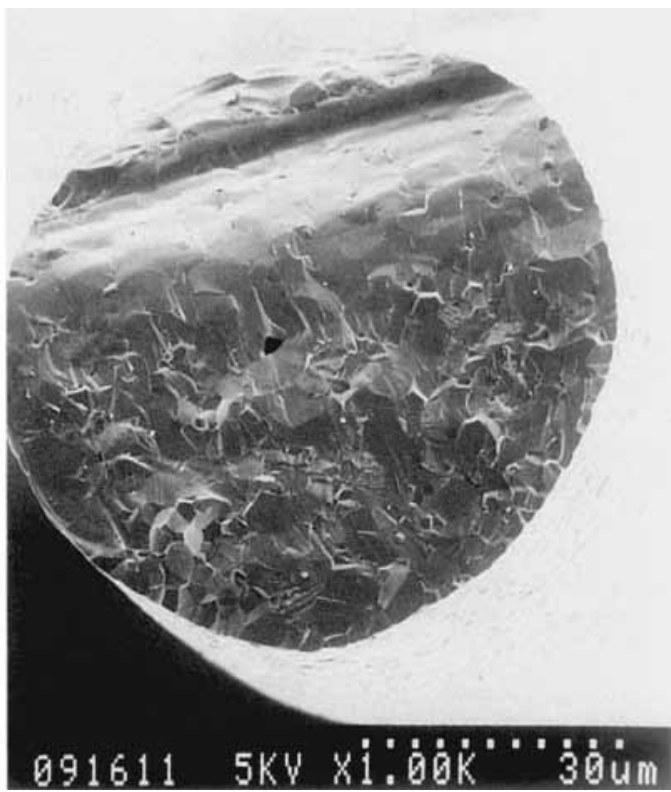

(b)

Fig. 4. SEM micrographs of fibers fired to $1700^{\circ} \mathrm{C}$ for $1 \mathrm{~h}(3000 \mathrm{X})$. As-fired surface (a) is dense and exhibits equiaxed grains of nearly uniform size. Fracture surface (b) is dense with the exception of voids formed due to dope inhomogeneity. The fiber exhibits a round cross section. 


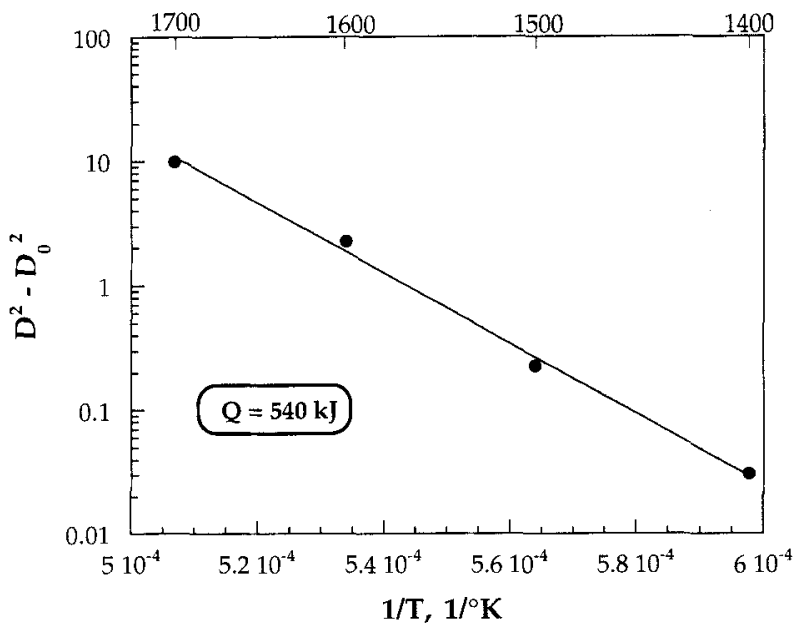

Fig. 5. Grain size as a function of reciprocal temperature for fibers fired to temperature for $1 \mathrm{~h}$. Good agreement between experimental data and normal grain growth kinetics is obtained with an apparent activation energy of $540 \mathrm{~kJ}$.

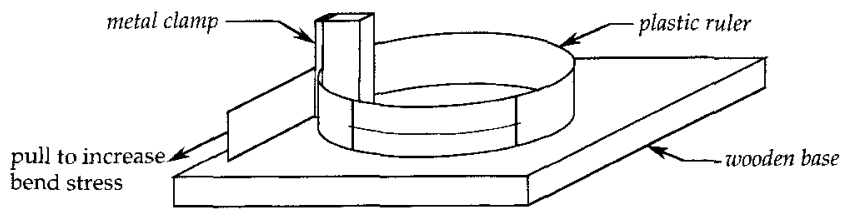

Fig. 6. Schematic of bend test fixture. Fiber is attached to the side of the plastic ruler.

observed on the fracture surfaces, but the stress level at these locations within the fiber was insufficient to cause fracture. The relative insensitivity of the bend test to internal defects is its main weakness.

\section{(3) Weibull Modulus Analysis}

The cumulative probability of failure at a given stress level is given by the general equation

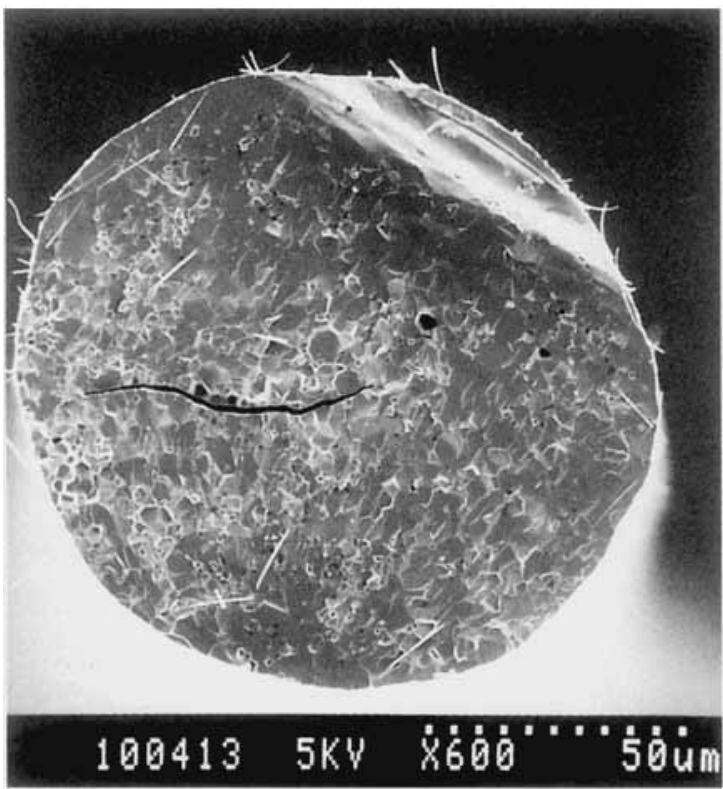

(a)

$$
F=1-\exp \left[-\int_{V}\left(\frac{\sigma}{\sigma_{0}}\right)^{m} \frac{\mathrm{d} V}{V_{0}}\right]
$$

where $\mathrm{d} V$ is the volume element, $V$ is the stressed volume, $V_{0}$ is the reference volume, $\sigma$ is stress on the volume element, $\sigma_{0}$ is a scaling factor, often taken to be the stress at which $F(\sigma)=$ 0.632 , and $m$ is the Weibull modulus. It is shown in the Appendix that the solution to this equation for the case of a fiber of circular cross section in pure bending is

$$
F=1-\exp \left[-2\left(l^{\prime}\right)\left(r^{\prime}\right)^{2}\left(\frac{\boldsymbol{\sigma}^{*}}{\boldsymbol{\sigma}_{0}}\right)^{m} f(m)\right]
$$

where $l^{\prime}$ is the normalized axial gage length, $r^{\prime}$ is the normalized fiber radius, $\sigma^{*}$ is the apparent fracture stress, and $f(m)$ is a function of the Weibull modulus. All constants can then be lumped together in a single constant, $A$. After rearrangement, the natural $\log$ of both sides is taken twice, and the following equation is obtained:

$$
\ln \ln \left[\frac{1}{1-F}\right]-\ln \left[l^{\prime}\right]=A+m \ln \left[\frac{\sigma^{*}}{\sigma_{0}}\right]
$$

which is the equation of a straight line of the form $y=b+m x$. The data were then plotted as $\ln \ln [1 /(1-F)]-\ln [l]$ vs $\ln$ $\left[\sigma^{*} / \sigma_{0}\right]$. Although independently derived here, a similar approach to the length effect has been suggested before. ${ }^{17,18}$

The data, plotted in Fig. 8, were linear with a Weibull modulus of 3.5. Note that, although linear, the data points do not increase monotonically as is usually observed in plots of cumulative frequency. This is due to the effect of the natural log of the fiber length appearing in the left-hand side of Eq. (6). Table I compares the Weibull modulus of the experimental YAG fibers to that of several different fibers. Although on the low side, the Weibull modulus observed for the experimental YAG fibers is within the range which can be expected for fibers.

\section{(4) Creep Resistance}

The creep resistance of the fibers was evaluated using the BSR technique. ${ }^{19,20}$ In this test, the fiber is bent to a known initial radius, $\rho_{0}$, imposing a surface strain given by $r / \rho_{0}$, where $r$ is the fiber radius. The fiber is then heated to the temperature at which it is to be evaluated and is held for a specified period

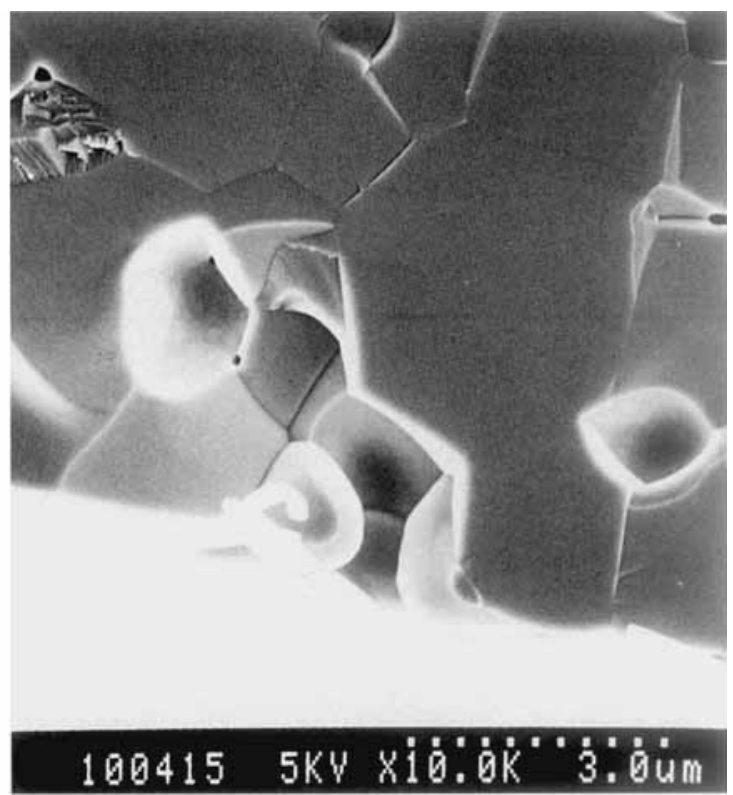

(b)

Fig. 7. Typical fracture surface (a) with fracture initiated at a surface flaw (b). The large, radial crack is due to drying shrinkage during processing and is not related to the bend test. 


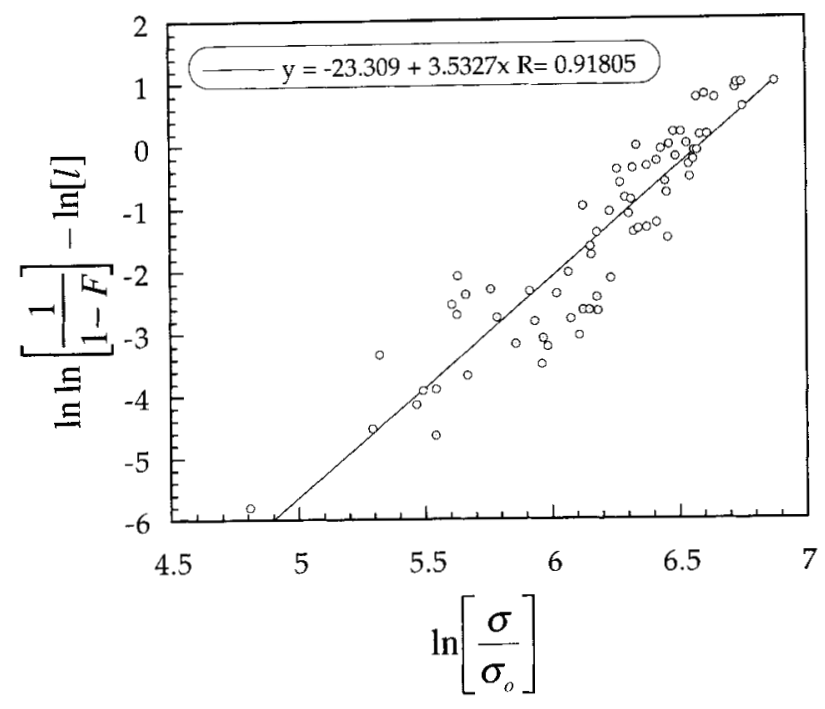

Fig. 8. Weibull plot of cumulative probability of failure with increasing stress. Scatter is due to the length effect.

Table I. Weibull Moduli of Several Different Fibers

\begin{tabular}{lc}
\hline Fiber & Weibull modulus, $m^{*}$ \\
\hline DuPont Fiber FP & 6.5 \\
Nicalon & 3 \\
Sumitomo $\mathrm{Al}_{2} \mathrm{O}_{3}$ & $4-6$ \\
$3 \mathrm{M}$ experimental $\mathrm{Al}_{2} \mathrm{O}_{3}$ & 8.9 \\
$\mathrm{UM}$ experimental $\mathrm{YAG}$ & 3.5 \\
\hline
\end{tabular}

*All data except for UM experinental YAG taken from M. A. Leitheiser and D. M. Wilson, "Advanced Fiber Development and Characterization: Volume IV-Alumina Fiber Development," NASP Contractor Report 1129, Vol. IV, Contract F3365787-C-2214, November 1991.

of time, usually $1 \mathrm{~h}$. At the end of the test, the imposed strain is removed. In the event that stress relaxation has taken place, the fiber will not return to its original shape, but will have a residual radius of bending, $\rho_{\mathrm{f}}$. This radius is then measured, and the stress relaxation ratio, $M$, may be found by

$$
M=1-\frac{\rho_{0}}{\rho_{\mathrm{f}}}
$$

A stress relaxation ratio of $1\left(\rho_{\mathrm{f}}=\infty\right)$ indicates no creep, whereas $M=0\left(\rho_{\mathrm{f}}=\rho_{0}\right)$ indicates complete stress relaxation. Although this test does not directly yield a steady-state creep rate, the test has been performed on a number of commercially available fibers, and so a large data base exists with which to compare the results of developmental fibers. ${ }^{14}$ The test was performed in air for a period of $1 \mathrm{~h}$ at various temperatures. The results are plotted in Fig. 9 as a function of reciprocal temperature, along with results from several commercially available oxide fibers. As can be seen, the creep resistance of the experimental YAG fibers represents a substantial improvement over the creep resistance of the commercially available polycrystalline oxide fibers. At a stress relaxation ratio of 0.5 , the creep resistance of the YAG fibers was increased by $220^{\circ} \mathrm{C}$ over PRD-166 and $275^{\circ} \mathrm{C}$ over Fiber FP alumina fibers. Only Saphikon sapphire fibers were more creep resistant than the YAG fibers; however, as Saphikon is c-axis oriented singlecrystal alumina, this is not surprising. A comparison of the steady-state creep rates of single-crystal alumina [0001] and single-crystal YAG [111] obtained by Corman ${ }^{3}$ (100 MPa and $1700^{\circ} \mathrm{C}$ ) to the steady-state creep rates for polycrystalline YAG obtained by Parthasarathy et al..$^{5}$ and extrapolated to the same conditions suggests that polycrystalline YAG creeps four orders of magnitude faster than single-crystal alumina and more than five orders of magnitude faster than single-crystal YAG. An obvious future direction for this research would be to perform the BSR test for different times to determine activation energy, and to perform the test on fibers which had been annealed for different times to determine grain size effects.

The BSR data were then used to predict tensile creep strain $\left(\varepsilon_{c}\right)$ after $1 \mathrm{~h}$ as a function of temperature through the relation ${ }^{19}$

$$
\varepsilon_{\mathrm{c}}(t, T, \sigma)=\left(\frac{\sigma}{E}\right)\left[\frac{1}{M}--1\right]
$$

by assuming a stress level $\sigma$ and substituting in the values of the stress relaxation ratio $(M)$ at various temperatures, $T$. This equation assumes relative insensitivity of $M$ to the applied stress. For comparison, the semiempirical equation developed by Parthasarathy et al. ${ }^{4}$ for compressive creep of polycrystalline YAG monoliths,

$$
\dot{\varepsilon}=\frac{4.52 \times 10^{-21}}{k T d^{2}} \exp \left(\frac{-584 \mathrm{~kJ} / \mathrm{mol}}{R T}\right) \sigma^{1.24}
$$

was used to calculate the creep strain of the monolithic materials as a function of temperature through the relation

$$
\varepsilon=\dot{\varepsilon} t
$$

$t$ was taken to be $3600 \mathrm{~s}(1 \mathrm{~h})$, as this was the length of the BSR tests, and the grain size $(d)$ was taken as $3 \times 10^{-6} \mathrm{~m}(3 \mu \mathrm{m})$. In both cases, a stress of $300 \mathrm{MPa}$ was assumed. The results of these calculations are shown in Fig. 10. Although the slopes of the two curve fits are not the same, the data points fall within the same general region, indicating reasonably good agreement.

\section{Conclusions}

Phase-pure YAG fibers were continuously dry spun from a dope prepared from aqueous colloidal sols and water-soluble polymers. Green fibers densified gradually over the range $1300^{\circ}-1600^{\circ} \mathrm{C}$, but were fully dense at $1700^{\circ} \mathrm{C}$. Reaction of $\mathrm{Al}_{2} \mathrm{O}_{3}$ and $\mathrm{Y}_{2} \mathrm{O}_{3}$ to $\mathrm{YAG}$ was complete just above $1300^{\circ} \mathrm{C}$. Large, radial cracks were observed in fibers whose green diameters were $\cong 150 \mu \mathrm{m}$. The appearance of these cracks was correlated with green fiber diameter and the amount of time between spinning and firing. The fired fibers exhibited an average bend strength of $522 \mathrm{MPa}$ and a Weibull modulus of 3.5, both limited by surface flaws which were thought to be processing related. Due to the nature of the bend test, the bend strength was unaffected by internal flaws such as the observed radial cracks. Creep resistance, evaluated using the bend stress relaxation test, was observed to be better than for all commercially available polycrystalline alumina fibers, despite the low

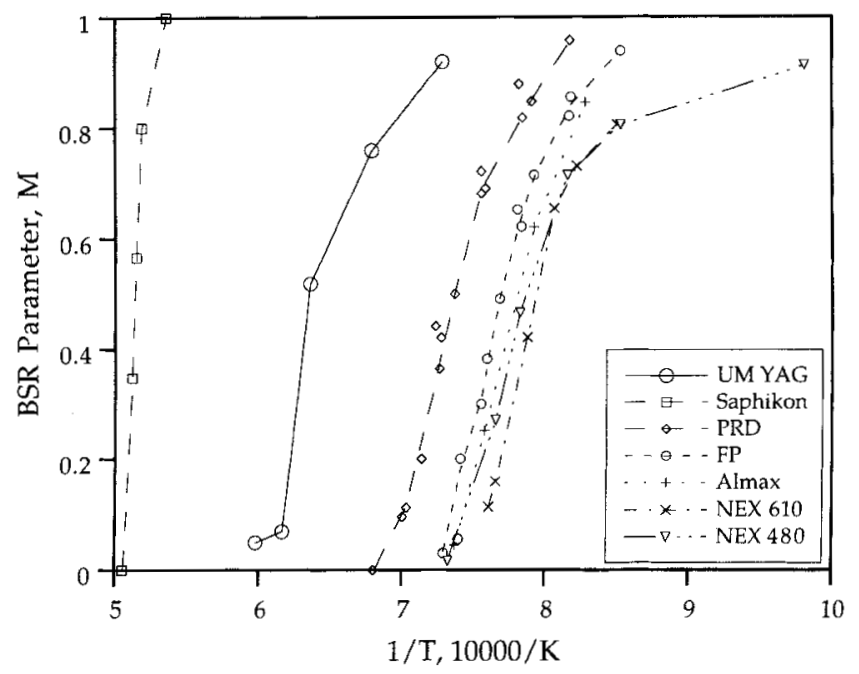

Fig. 9. One-hour stress relaxation ratio vs reciprocal temperature for experimental YAG fibers and several commercially available fibers. Experimental YAG fibers are more creep resistant than all of the commercially available fibers except Saphikon. 


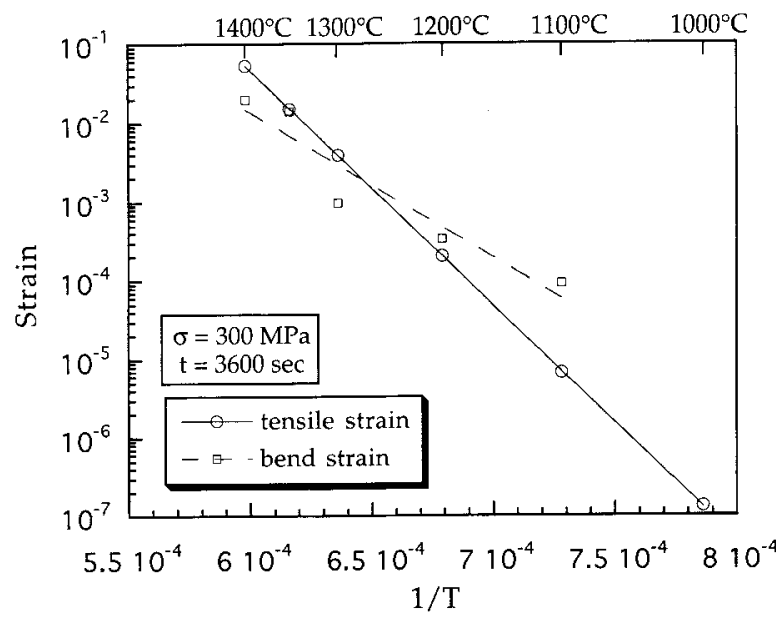

Fig. 10. Tensile creep strain predictions based on BSR results compared with compressive creep strain observed in polycrystalline YAG monoliths. ${ }^{4}$

strength of the fibers. The predicted tensile creep strain of the YAG fibers coincided well with the observed creep strain of polycrystalline YAG monoliths of the same grain size. With improvements in processing, the superior creep resistance of YAG fibers makes them candidates for future high-temperature applications.

\section{APPENDIX}

\section{Weibull Modulus Derivation}

A two-parameter form of the Weibull function

$$
F=1-\exp \left[-\int_{V}\left(\frac{\sigma}{\sigma_{0}}\right)^{m} \frac{\mathrm{d} V}{V_{0}}\right]
$$

where $\mathrm{d} V$ is the volume element, $V$ is the stressed volume, $V_{0}$ is the reference volume, $\sigma$ is stress on the volume element, $\sigma_{0}$ is a scaling factor, often taken to be the stress at which $F(\sigma)=$ 0.632 , and $m$ is the Weibull modulus, is used to determine the form of the Weibull equation for the case of circular fibers of varying lengths tested in bending. Pure bending is assumed, so that the stress at a given distance from the neutral plane is constant along the length of the fiber. Therefore, the stress at any distance from the neutral plane can be found by

$$
\sigma=\frac{E z}{\rho}
$$

Figure A1 shows a schematic of the fiber cross section. Bending occurs in the negative $z$-direction, and the neutral plane intersects the $x$-axis. $\mathrm{d} V$ is taken to be a narrow strip running parallel

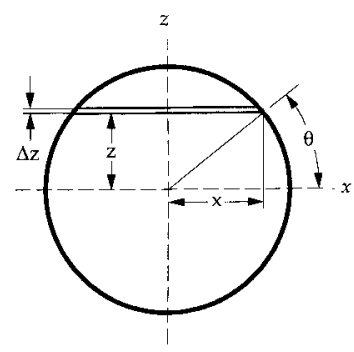

Fig. A1. Schematic fiber cross section showing volume element used for Weibull modulus derivation. to the neutral plane, and only the tensile half of the fiber is considered. The volume element is then given by

$$
\mathrm{d} V=2 x l \mathrm{~d} z
$$

However, $x$ is a function of $z$. Cylindrical coordinates may be used to write Eqs. (A-2) and (A-3) in terms of a single variable, $\theta$; thus

$$
\sigma=\frac{E r \sin \theta}{\rho}
$$

and

$$
\mathrm{d} V=2 / r^{2} \cos ^{2} \theta \mathrm{d} \theta
$$

Making the appropriate substitutions and rearranging, Eq. (A-1) becomes

$$
F=1-\exp \left[-2 \frac{l r^{2}}{V_{0}}\left(\frac{E r}{\sigma_{0} \rho}\right)^{m} \int_{0}^{\pi / 2} \sin ^{m} \theta \cos ^{2} \theta \mathrm{d} \theta\right]
$$

The integral in Eq. (A-4) cannot be solved symbolically for noninteger values of $m$; however, a numerical solution exists. The value of the integral drops rapidly from 0.33 at $m=1$ to 0.076 at $m=5$, then drops gradually to 0.032 at $m=10$. For convenience, the integral is replaced with an arbitrary function of $m, f(m)$. The reference volume, $V_{0}$, can arbitrarily be chosen to be $1 \mathrm{~cm}^{3}$, and therefore may be replaced by $l_{0} r_{0}^{2}$, where $l_{0}=$ $r_{0}=1 \mathrm{~cm}$. Then making the substitution

$$
\sigma^{*}=\frac{E r}{\rho}
$$

where $\sigma^{*}$ is the apparent bend strength, Eq. (A-4) becomes

$$
F=1-\exp \left[-2\left(\frac{l}{l_{0}}\right)\left(\frac{r}{r_{0}}\right)^{2}\left(\frac{\sigma^{*}}{\sigma_{0}}\right)^{m} f(m)\right]
$$

Replacing $l / l_{0}$ and $r / r_{0}$ with the dimensionless quantities $l^{\prime}$ and $r^{\prime}$, rearranging and taking the natural $\log$ of both sides twice yields

$$
\ln \ln \left[\frac{1}{1-F}\right]=\ln \left[2\left(r^{\prime}\right)^{2} f(m)\right]+\ln \left[l^{\prime}\right]+m \ln \left[\frac{\sigma^{*}}{\sigma_{0}}\right]
$$

The term $2\left(r^{\prime}\right)^{2} f(m)$ is a constant (since $r$ is known and $f(m)$ is a function of Weibull modulus only) and may be replaced by an arbitrary constant $A$. However, $l^{\prime}$ is not a constant, since fibers of different lengths were used for many of the tests. The term ln $\left(l^{\prime}\right)$ can then be moved to the left-hand side of the equation to yield

$$
\ln \ln \left[\frac{1}{1-F}\right]-\ln \left[l^{\prime}\right]=A+m \ln \left[\frac{\sigma^{*}}{\sigma_{0}}\right]
$$

which is the equation of a straight line with $y$-intercept $A$ and slope $m$.

Acknowledgment: The authors wish to thank Greg Morscher of NASA Lewis Research Center, Cleveland, $\mathrm{OH}$, for the use of his facilities and expertise in performing the creep measurements.

\section{References}

'L. E. Jones, S. A. Newcomb, and R. E. Tressler, "Creep and Rupture Behavior of Single Crystal Sapphire Filaments"; pp. 47-1 to 47-16 in HITEMP Review 1990: Advanced High Temperature Engine Material's Technology Program, NASA Report No. CP-10051, 1990.

${ }^{2}$ D. J. Pysher, K. C. Goretta, R. S. Hodder Jr., and R. E. Tressler, "Strengths of Ceramic Fibers at Elevated Temperatures," J. Am. Ceram. Soc., 72 [2] 284-88 (1989).

${ }^{3}$ G. S. Corman, "High Temperature Creep of Some Single Crystal Oxides," Ceram. Eng. Sci. Proc., 12 [9-10] 1745-66 (1991).

${ }^{4}$ T. A. Parthasarathy, T. Mah, and K. Keller, "High Temperature Deformation Behavior of Polycrystalline Yttrium Aluminum Garnet (YAG)," Ceram. Eng. Sci. Proc, 12 [9-10] 1767-73 (1991). 
${ }^{5}$ T. A. Parthasarathy, T. Mah, and K. Keller, "Creep Mechanism of Polycrystalline Yttrium Aluminum Garnet," J. Am. Ceram. Soc., 75 [7] 1756-59 (1992).

${ }^{6} \mathrm{~K}$. Keller, T. Mah, and T. A. Parthasarathy, "Processing and Mechanical Properties of Polycrystalline $\mathrm{Y}_{3} \mathrm{Al}_{5} \mathrm{O}_{12}$ (Ytrrium Aluminum Garnet)," Ceram. Eng. Sci. Proc, 11 [7-8] 1122-33 (1990).

${ }^{7}$ T. Mah, T. A. Parthasarathy, and L. E. Matson, "Processing and Mechanical Properties of $\mathrm{Al}_{2} \mathrm{O}_{3}-\mathrm{Y}_{3} \mathrm{Al}_{5} \mathrm{O}_{12}$ (YAG) Eutectic Composite," Ceram. Eng. Sci. Proc., 11 [9-10] 1617-27 (1990).

${ }^{8} \mathrm{~T}$. A. Parthasarathy and T. Mah, "Deformation Behavior of an $\mathrm{Al}_{2} \mathrm{O}_{3}-$ $\mathrm{Y}_{3} \mathrm{Al}_{5} \mathrm{O}_{12}$ Eutectic Composite in Comparison with Sapphire and YAG," $J$. Am. Ceram. Soc., 76 [1] 29-32 (1993).

${ }^{9} \mathrm{G}$. N. Morscher, K. C. Chen, and K. S. Mazdiyasni, "Creep Resistance of Developmental Polycrystalline Yttrium-Aluminum Garnet Fibers," Ceram. Eng. Sci. Proc., 15 [4] 181-88 (1994).

${ }^{10}$ T. Mah, T. A. Parthasarathy, M. D. Petry, and L. E. Matson, "Processing, Microstructure, and Properties of $\mathrm{Al}_{2} \mathrm{O}_{3}-\mathrm{Y}_{3} \mathrm{Al}_{5} \mathrm{O}_{12}$ (YAG) Eutectic Fibers," Ceram. Eng. Sci. Proc., 14 [7-8] 622-38 (1993).

${ }^{1 ' M a n u f a c t u r e r ' s ~ d a t a ~ s h e e t . ~}$

${ }^{12}$ B. King. Y. Liu, S. Baskaran, R. Laine, and J. Halloran, "Yttrium Aluminate Ceramic Fibers via Pre-Ceramic Polymer and Sol-Gel Routes," Part. Sci. Technol., 10, 121-32 (1992).
${ }^{13}$ B. H. King, Y. Liu, R. M. Laine, and J. W. Halloran, "Fabrication of Yttrium Aluminate Fibers," Ceram. Eng. Sci. Proc., 14 [7-8] 639-50 (1993).

${ }^{14} \mathrm{G}$. N. Morscher and H. Sayir, "Thermomechanical Bend Properties of Single Crystal and Polycrystalline Alumina-Based Fibers"; presented at 16th Conference on Metal Matrix, Carbon and Ceramic Matrix Composites (Restricted Sessions), Cocoa Beach, FL, Jan. 12-15, 1992, Report No. NASA-3175, pp. $657-75$.

${ }^{15}$ P. A Siemers, R. L. Mehan, and H. Moran "A Comparison of the Uniaxial Tensile and Pure Bending Strength of SiC Filaments," J. Mater. Sci., 23, 1329-33 (1988)

${ }^{16} \mathrm{Z}$. Li and R. C. Bradt, "Micromechanical Stresses in Sapphire Whisker and Alumina Fiber Reinforced Mullite and Garnet Ceramic Matrix Composites," J. Eur. Ceram. Soc., 9, 143-52 (1992).

${ }^{17}$ S. van der Zwaag, "The Concept of Filament Strength and Weibull Modulus." J. Test. Eval. 17 [5] 292-98 (1989)

${ }^{18}$ D. R. Roberts, E. Cuellar, M. T. Kennedy, and J. E. Ritter Jr., "Calculation of Static Fatigue Lifetime of Optical Fiber," Opt. Eng., 30 [6] 716-27 (1991).

${ }^{19} \mathrm{G}$. N. Morscher, J. A. DiCarlo, and T. Wagner, "Fiber Creep Evaluation by Stress Relaxation Measurements," Ceram. Eng. Sci. Proc., 12 [7-8] 1032-38 (1991).

${ }^{20} \mathrm{G}$. N. Morscher and J. A. DiCarlo, "A Simple Test for Thermomechanical Evaluation of Ceramic Fibers," I. Am. Ceram. Soc., 75 [1] 136-40 (1992). 